\title{
An integrated single-vendor single-buyer production-inventory model for items with imperfect quality and inspection errors
}

\author{
J.T. Hsu ${ }^{\mathrm{a}}$ and L.F. Hsu ${ }^{\mathbf{b}}$
}

${ }^{a}$ Department of Computer Science and Information Engineering, Hungkuang University, Shalu, Taichung 43302, Taiwan

${ }^{b}$ Department of Management, Baruch College, The City University of New York, One Bernard Baruch Way, BOX B9-240, New York, NY 10010, USA

ARTICLEINFO ABSTRACT

\section{Article history:}

Received 5 April 2012

Accepted April 202012

Available online

21 April 2012

Keywords:

$E O Q$

Imperfect quality

Misclassification errors

Supply chain

\begin{abstract}
In this paper, we develop an integrated vendor-buyer production-inventory model for items with imperfect quality and inspection errors. The production process is imperfect and produces a certain number of defective items with a known probability density function. We consider the policy in which the delivery quantity to the buyer is identical at each shipment. Once the buyer receives the lot, a $100 \%$ screening process of the lot is conducted, and the screening process and demand proceed simultaneously. The screening process is not perfect. The inspector may incorrectly classify a non-defective item as defective, or incorrectly classify a defective item as non-defective. The expected integrated total annual cost of the vendor and the buyer is derived and a solution procedure is provided to find the optimal solution. Numerical examples show that the integrated model gives an impressive cost reduction in comparison to an independent decision by the buyer.
\end{abstract}

(C) 2012 Growing Science Ltd. All rights reserved

\section{Introduction}

With the growing focus on supply chain management in the past few decades, firms have been attempting to achieve greater collaborative advantages with their supply chain partners. Since firms realize that inventory across the supply chain can be more efficiently managed through greater cooperation and better coordination, integrated inventory management has recently received a great deal of attention. Goyal (1976) considered the joint optimization problem of a single vendor and a single buyer, in which he assumed that the vendor's production rate is infinite. Banerjee (1986) assumed a finite rate of production and developed a joint economic-lot-size model for the product with a lot-for-lot shipment policy. Goyal (1988) developed a joint total relevant cost model for a singlevendor single-buyer production inventory system in which each production batch was shipped to the buyer in smaller lots of equal size. Goyal and Gupta (1989) reviewed the related literature in integrated vendor-buyer inventory models. Aderohunmu et al. (1995) showed that a significant cost reduction could be achieved to the advantage of both the vendor and the buyer in a just-in-time environment when timely cost information was shared between the parties.

* Corresponding author. Tel. +1-646-312-3656

E-mail: Lie-Fern.Hsu@baruch.cuny.edu (L.F.Hsu)

(c) 2012 Growing Science Ltd. All rights reserved.

doi: 10.5267/j.ijiec.2012.04.004 
Lu (1995) considered the single-vendor multi-buyer integrated inventory problem with the objective of minimizing the vendor's total cost subject to the maximum costs which the buyers were prepared to incur. Goyal (1995) suggested an approach that was capable of obtaining lower total joint relevant costs of the single-vendor single-buyer production inventory systems; i.e., the ratio between the $(\mathrm{i}+1) \mathrm{st}$ shipment and the ith shipment is equal to the ratio between the vendor's production rate and the demand rate of the buyer. Hill (1997) illustrated that, in general, neither of the two policies described in Lu (1995) and Goyal (1995) would be optimal. Ha and Kim (1997) developed an integrated just-in-time lot-splitting model of facilitating multiple shipments in small lots of a single-vendor-single-buyer system under deterministic conditions for a single product, and showed that when the integrated optimal policy was adopted by both the vendor and the buyer in a cooperative manner, both parties could benefit. Viswanathan (1998) presented the results of a detailed numerical study that analyzed the relative performance of the two different strategies of equal- and unequal-sized batch shipments as described in Lu (1995) and Goyal (1995). The numerical study showed that neither strategy dominated the other for all problem parameters. In other words, the best policy for the model depended on the specific problem parameters.

Hill (1999) determined the optimal production and inventory policy for a vendor manufacturing to supply to a single buyer. The policy turned out to be a combination of Goyal's (1995) policy and an equal shipment size policy. Hoque and Goyal (2000) extended the idea of Goyal and Szendrovits (1986) and developed an optimal solution procedure for the single-vendor single-buyer integrated production-inventory system with both equal and unequal sized shipments, in which capacity constraint of the transport equipment was considered. Goyal and Nebebe (2000) considered the problem of determining economic production and the shipment policy of a product supplied by a vendor to a buyer. The objective was to minimize the total joint costs incurred by the vendor and the buyer. Wu and Ouyang (2003) considered the integrated single-vendor single-buyer inventory system with shortage. They proposed an algebraic procedure to find the optimal order quantity, the maximum shortage level, and the optimal number of deliveries from the vendor to the buyer per order of the integrated total cost of the vendor and the buyer without using differential calculus. Ouyang et al. (2004) considered a stochastic lead time demand and assumed that shortages could happen during lead time, and lead time could be reduced at an added cost.

Chang et al. (2006) studied the lead time and ordering cost reduction problem in the single-vendor single-buyer integrated inventory model. Hill and Omar (2006) revisited the single-vendor single-buyer integrated production inventory problem by allowing the holding cost to decrease down the supply chain. Hoque and Goyal (2006) developed a heuristic solution procedure to minimize the total cost of setup or ordering, inventory holding and lead time crashing for an integrated inventory system under controllable lead time between a vendor and a buyer. Sarmah et al. (2006) reviewed literature dealing with buyer vendor coordination models that have used quantity discount as a coordination mechanism under a deterministic environment and classified the various models. Siajadi et al. (2006) presented a new methodology to obtain the joint economic lot size in the case where multiple buyers were demanding one type of item from a single vendor. Chan and Kingsman (2007) proposed a coordinated single-vendor multi-buyer supply chain by synchronizing delivery and production cycles. Ertogral et al. (2007) incorporated transportation cost explicitly into a joint vendor-buyer inventory model under equal-shipment policy. Zhou and Wang (2007) developed a more general production-inventory model for a single-vendor-single-buyer integrated system. Their model neither requires that the buyer's unit holding cost be greater than the vendor's nor assumes the structure of shipment policy. Other studies on the joint economic lot sizing problem up to the year 2007 can be found in Ben-Daya et al.(2008). Chung (2008) showed that Wu and Ouyang's (2003) proof of a global cost minimum was incomplete. He then justified the algorithm described in Wu and Ouyang (2003). Ben-Daya and Al-Nassar (2008) developed a cost minimization supply chain coordination model for a three-layer supply chain 
involving suppliers, manufacturers, and retailers, and derived a solution procedure for the model. Huang et al. (2010a, 2010b), by using different cost structures for the two studies, incorporated orderprocessing cost reduction and permissible delay in payments into the integrated vendor-buyer inventory policy.

The classical economic order quantity (EOQ) model assumes that items produced are of perfect quality, which is usually not the case in real production. Porteus (1986) introduced a model that showed a significant relationship between quality and lot size. Lee and Rosenblatt (1987) addressed the problem of joint control of production cycles or manufacturing quantities, and maintenance by inspections. Schwaller (1988) extended the EOQ model by adding the assumptions that defective items of a known proportion were present in incoming lots, and that fixed and variable inspection costs were incurred in finding and removing these defective items. It was also assumed that the supplier reimbursed the buyer for any defective items found and removed. Ben-Daya and Hariga (2000) studied the effect of imperfect production processes on the economic lot sizing policy (ELSP). They developed a mathematical model for ELSP, taking into account the effect of imperfect quality and process restoration. Salameh and Jaber (2000) developed an economic order quantity model where a random proportion of the items in a lot are defective.

Huang (2002) extended the integrated vendor-buyer inventory model by accounting for imperfect quality items. He considered the situation where the delivery quantity sent to the buyer was identical for each shipment. Goyal et al. (2003) used the Goyal and Cárdenas-Barrón (2002) model to determine an optimal integrated vendor-buyer inventory policy for an item with imperfect quality. Huang (2004) extended the model of Ha and Kim (1997) by incorporating imperfect items into the productioninventory model. Lo et al. (2007) assumed a varying rate of deterioration, partial backordering, inflation, imperfect production processes, and multiple deliveries, and developed an integrated production and inventory model from the perspectives of both the manufacturer and the retailer.

Cárdenas-Barrón (2009) developed an economic production quantity (EPQ) inventory model with planned backorders for determining the economic production quantity and the size of backorders for a single product, which was made in a single-stage manufacturing process that generated imperfect quality products and required that all defective products be reworked at the same cycle. Sana (2010) investigated an EPL (Economic Production Lot size) model in an imperfect production system in which the production facility could shift from an 'in-control' state to an 'out-of-control' state at any random time. He formulated the model assuming that a certain percent of total product was defective (imperfect) in an 'out-of-control' state. This percentage also varied with production rate and production run time. Chung (2011) revisited the work of Cárdenas-Barrón (2009) and developed the sufficient and necessary condition for the existence of the solution satisfying the first derivative condition of the annual total relevant cost and presented a concrete solution procedure to find the optimal solution. Liao and Sheu (2011) described an integrated EPQ model that incorporated EPQ and maintenance programs. For more recent works on inventory models with imperfect quality items, we refer the readers to Khan et al. (2011a).

The Salameh and Jaber (2000) model assumed that there is no human error in the screening process. Raouf et al.(1983) studied human errors in inspection. They came up with one of the first inspection plans with misclassifications for multi-characteristic critical components. Duffuaa and Khan (2002) proposed a general inspection plan for quality assurance of critical multi-characteristic components. They extended the Raouf et al.(1983) inspection plan for the case of six types of misclassification errors, where an inspector could classify an item to be good, rework or scrap. Duffuaa and Khan (2005) carried out a sensitivity analysis to investigate the statistical and economic impact of the several types of misclassification errors on the performance measures of the inspection plan. Kok and Shang (2007) studied a single-period inventory system with inventory record inaccuracy. Yoo et al. (2009) proposed a profit-maximizing economic production quantity model that incorporated both imperfect production quality and two-way imperfect inspection; i.e., the Type I inspection error of incorrectly classifying a 
non-defective item as defective and the Type II inspection error of incorrectly classifying a defective as non-defective. Lin (2009) developed a production-inventory model for a simple supply chain system with defective items and inspection errors, where he assumed that both the Type I and Type II inspection errors are known constants. Khan et al. (2011b) extended the work of Salameh and Jaber (2000) model by assuming that the inspection process was not error-free. Hsu (2012) pointed out a contradiction in Khan et al.'s (2011b) mathematical model and developed a corrected EOQ.

The purpose of this paper is to develop an integrated vendor-buyer inventory model with imperfect product quality and inspection errors. The rest of this paper is organized as follows: In section 2, the notation and assumptions used in this paper are introduced. In section 3, we develop a mathematical model that integrates the vendor's and the buyer's annual cost and takes into consideration imperfect production processes and inspection errors. Section 4 provides a numerical example and its sensitivity analysis to various parameters to illustrate important aspects of the model. Finally, in section 5 we summarize and conclude the paper and provide directions for future research.

\section{Notation and assumptions}

We consider a two-stage supply chain problem with a single vendor and a single buyer. The buyer has an annual demand of $D$ units for the given product, and places regular orders of fixed size $Q_{P}$. The vendor prepares for the repeating flow of orders of size $Q_{P}=n Q$ from the buyer by producing items in batches of size $Q_{P}$ and by planning to have each batch delivered to the buyers in $n$ deliveries, each with a lot of $Q$ units. The vendor fulfills the deliveries of $Q$ units with a known and fixed lead time. Since the production system is not perfect, some of the items produced may be defective. Once the buyer receives the items, a $100 \%$ screening process is conducted. We assume the screening process and demand take place simultaneously. The screening process is also not perfect, involving Type I and Type II inspection errors. The objective is to minimize the total joint annual costs incurred by the vendor and the buyer. The following notation and assumptions are used in our model:

$Q_{P} \quad$ the size of a production batch of items at the vendor

$Q \quad$ the size of the deliveries from the vendor to the buyer

$n \quad$ the number of deliveries per batch production run, a positive integer $\left(Q_{P}=n Q\right)$

$D \quad$ the annual demand of the buyer

$P \quad$ the annual production rate $(P>D)$ at the vendor

$x \quad$ the screening (inspection) rate

$S_{v} \quad$ the setup cost per production run for the vendor

$S_{B} \quad$ the ordering cost per order for the buyer

$\gamma \quad$ the probability that an item produced is defective

$f(\gamma)$ the probability density function of $\gamma$

$e_{1} \quad$ the probability of a Type I error (classifying a non-defective item as defective)

$f\left(e_{1}\right)$ the probability density function of $e_{1}$

$e_{2} \quad$ the probability of a Type II error (classifying a defective item as non-defective)

$f\left(e_{2}\right)$ the probability density function of $e_{2}$

$c_{i} \quad$ the buyer's inspection cost per unit

$c_{w}$ the vendor's unit cost for producing a defective item

$c_{a B}$ the buyer's cost of a post-sale defective item

$c_{a v}$ the vendor's cost of a post-sale defective item

$c_{a}$ the cost of accepting a defective item $\left(c_{a}=c_{a B}+c_{a v}\right)$

$c_{r} \quad$ the cost of rejecting a non-defective item 
$h_{v} \quad$ the holding cost per unit per year for the vendor

$h_{B} \quad$ the holding cost per unit per year for the buyer

$F \quad$ the freight (transportation) cost per delivery (including the delivery of $Q$ units from the vendor to the buyer and the returned items from the buyer to the vendor)

$B_{1} \quad$ the number of items that are classified as defective in each delivery of $Q$ units

$B_{2} \quad$ the number of items that are returned from the market in each delivery of $Q$ units

$T \quad$ the time interval between successive deliveries of $Q$ units

$T_{1} \quad$ the period during which the vendor produces

$T_{2} \quad$ the period during which the vendor supplies from inventory

$T_{c} \quad$ the cycle time $=T_{1}+T_{2}=n T$

* the superscript representing optimal value

Assumptions:

1. The demand rate is known, constant, and continuous.

2. The lead time is known and constant.

3. The production processes are imperfect and may produce defective items. The defective percentage $\gamma$ has a probability density function $f(\gamma)$.

4. The inspection process is also imperfect. The probability of classifying a non-defective item as defective is $e_{1}$ with a probability density function $f\left(e_{1}\right)$.

5. The probability of classifying a defective item as non-defective is $e_{2}$ with a probability density function $f\left(e_{2}\right)$.

6. The buyer returns all items classified as defective and those returned from the customers to the vendor at the end of the $100 \%$ screening process, and receives a full price refund from the vendor. Thus, a defective item incurs a cost of $c_{w}$ for the vendor. The vendor will sell the returned items at a discounted price to a secondary market. Therefore, $c_{r}$ (the cost of rejecting a non-defective item) is the difference between the regular and the discounted prices.

7. Customers who buy the defective items will detect the quality problem and return them to the buyer and receive a good (replaced) item from the buyer. Both the vendor and the buyer incur a post-sale failure cost (e.g., loss of good will) for the items returned from the market.

8. Shortages are not allowed.

9. A single product is considered.

10. There is a single vendor and a single buyer.

\section{Mathematical model}

\subsection{The buyer's cost per cycle}

Consider a lot of size $Q$ being delivered to the buyer. It is assumed that the lot is $100 \%$ screened at the beginning of each replenishment cycle. Each lot contains a percentage $\gamma$ of defective items with the probability density function $f(\gamma)$. While screening the items, an inspector may incorrectly classify a non-defective item as defective with probability $e_{1}$ and the probability density function $f\left(e_{1}\right)$, or the 
inspector may incorrectly classify a defective item as non-defective with probability $e_{2}$ and the probability density function $f\left(e_{2}\right)$. It is assumed that the buyer returns all the items classified as defective by the inspector and the items returned from the market to the vendor as a single batch at the end of the screening process and receives a full price refund from the vendor. Thus, each defective item will incur a cost of $c_{w}$ and each non-defective item classified as defective will incur a cost of $c_{r}$ for the vendor. For example, if the production cost is $\$ 30 /$ unit, the regular selling price is $\$ 50 /$ unit, and the discounted selling price is $\$ 20 /$ unit, then $c_{w}=\$ 10$ and $c_{r}=\$ 30$. For each item being returned from the market, the buyer and the vendor incur a post-sale failure cost (e.g., the loss of good will) $c_{a B}$ and $c_{a v}$ respectively. If the vendor and the buyer do not work together in a cooperative manner towards maximizing their mutual benefits, and the buyer makes his own decisions independent of the vendor, then the vendor will produce and deliver the items to the buyer on a lot-for-lot basis. Fig. 1 illustrates the behavior of the inventory level over time for the buyer.

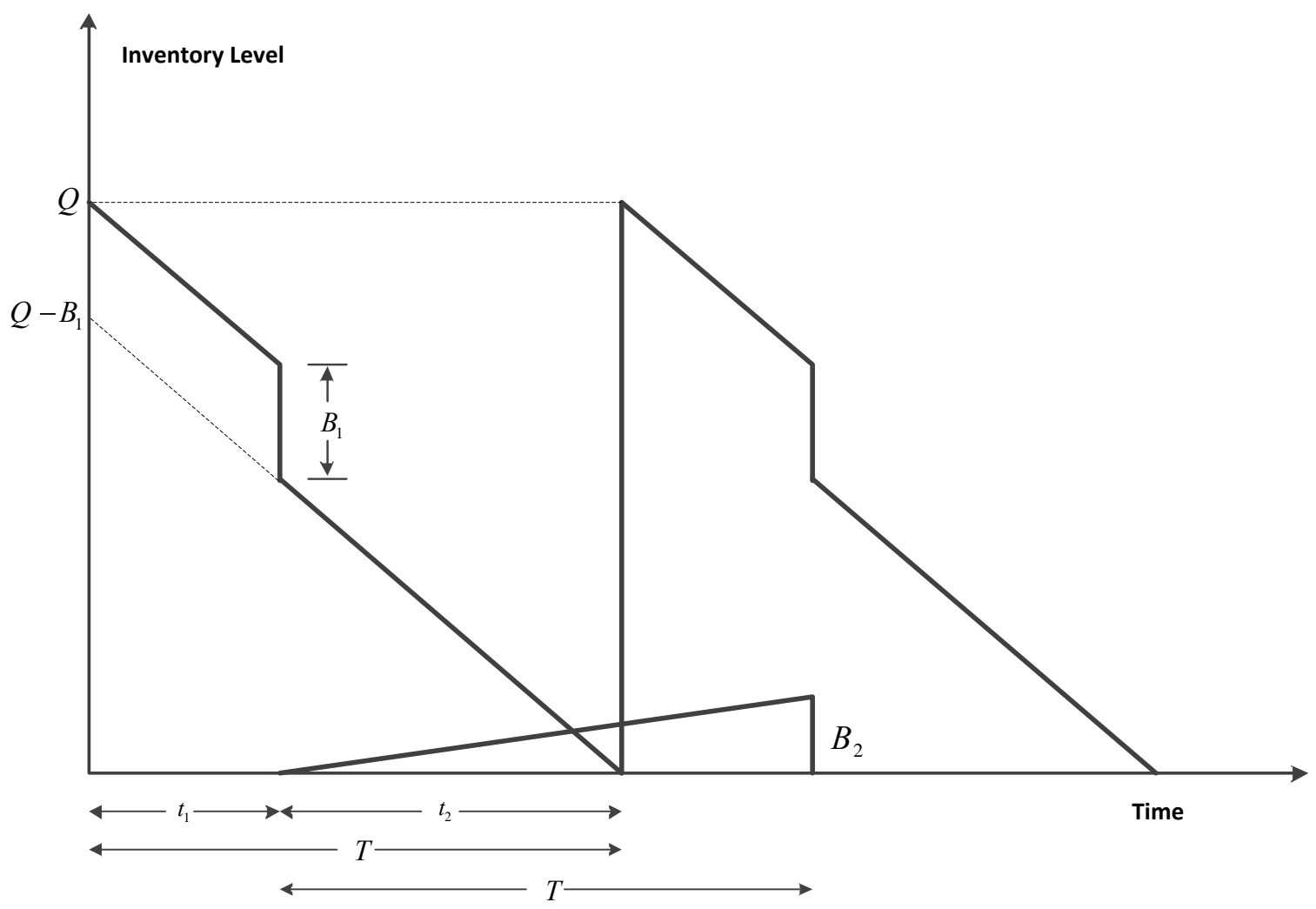

\section{Inventory Level}

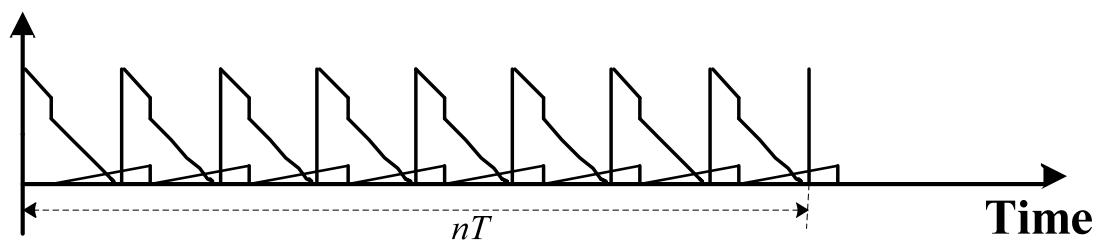

Fig.1. Behavior of the buyer's inventory level over time

By definition, we have

$B_{1}=Q(1-\gamma) e_{1}+Q \gamma\left(1-e_{2}\right)$ 
and

$$
B_{2}=Q \gamma e_{2} .
$$

We assume that for each item returned from the market, a good item is replaced for the customer. Based on this assumption, there are two streams of demand; namely, the regular demand and the demand to replace the returned items. Let $D^{\prime}$ be the effective demand; then we have $D^{\prime}=D+B_{2} / T$. By definition, the cycle length of each delivery of size $Q$ is $T=\left(Q-B_{1}\right) / D^{\prime}$. Substituting $D^{\prime}=D+B_{2} / T$ and solving the equation, we have

$$
T=\frac{\left(Q-B_{1}-B_{2}\right)}{D}=\frac{Q(1-\gamma)\left(1-e_{1}\right)}{D} .
$$

The holding cost per delivery cycle is

$$
H C=h_{B}\left\{B_{1} t_{1}+\frac{\left(Q-B_{1}\right) T}{2}\right\}+h_{B}\left(\frac{B_{2} T}{2}\right) .
$$

Substituting $t_{1}$ with $Q / x, B_{1}$ with $Q(1-\gamma) e_{1}+Q \gamma\left(1-e_{2}\right), B_{2}$ with $Q \gamma e_{2}$ and $T$ with $Q(1-\gamma)\left(1-e_{1}\right) / D$, the holding cost per delivery cycle is given by

$$
H C=h_{B}\left\{\frac{Q^{2}}{x}\left[(1-\gamma) e_{1}+\gamma\left(1-e_{2}\right)\right]+\frac{Q^{2}\left\{1-\left(e_{1}+\gamma\right)+\gamma\left(e_{1}+2 e_{2}\right)\right\}(1-\gamma)\left(1-e_{1}\right)}{2 D}\right\} .
$$

After adding the ordering, transportation, inspection, and post-sale failure costs, the cost per production cycle for the buyer is

$$
\begin{aligned}
& T C_{B}(n, Q)=S_{B}+n F+n c_{i} Q+n c_{a B} Q \gamma e_{2} \\
& +n h_{B}\left\{\frac{Q^{2}}{x}\left[(1-\gamma) e_{1}+\gamma\left(1-e_{2}\right)\right]+\frac{Q^{2}\left\{1-\left(e_{1}+\gamma\right)+\gamma\left(e_{1}+2 e_{2}\right)\right\}(1-\gamma)\left(1-e_{1}\right)}{2 D}\right\} .
\end{aligned}
$$

\subsection{The vendor's cost per cycle}

Fig. 2 shows the vendor's holding cost per cycle can be obtained as (see, for example, Goyal et al. (2003) and Huang (2004)).

Holding cost per cycle $=h_{v}$ [bold area - shaded area $]$

$$
\begin{aligned}
& =h_{v}\left\{\left[n Q\left(\frac{Q}{P}+(n-1) T\right)-\frac{n Q(n Q / P)}{2}\right]-T[Q+2 Q+\ldots+(n-1) Q]\right\} \\
& =h_{v}\left\{\left[n Q\left(\frac{Q}{P}+(n-1) \frac{Q(1-\gamma)\left(1-e_{1}\right)}{D}\right)-\frac{n Q(n Q / P)}{2}\right]-\frac{Q(1-\gamma)\left(1-e_{1}\right)}{D}[Q+2 Q+\ldots+(n-1) Q]\right\} \\
& =h_{v}\left\{\frac{n Q^{2}}{P}-\frac{n^{2} Q^{2}}{2 P}+\frac{n(n-1) Q^{2}(1-\gamma)\left(1-e_{1}\right)}{2 D}\right\} .
\end{aligned}
$$




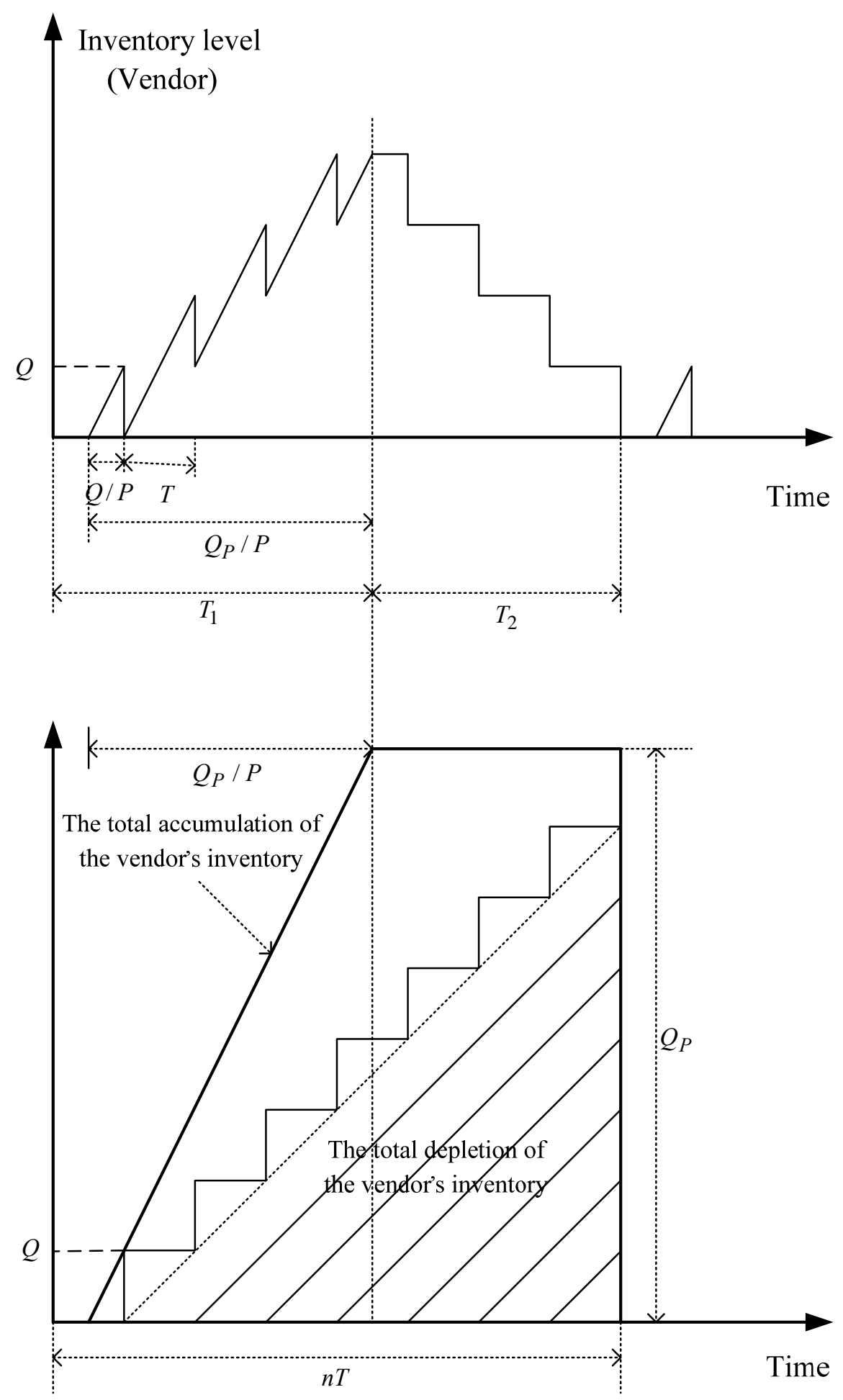

Fig. 2.Time-weighted inventory for the vendor

After adding the costs of setup, warranty, and Type I and Type II errors, the vendor's total cost per cycle $T C_{v}(n, Q)$ is

$T C_{v}(n, Q)=S_{v}+n c_{w} Q \gamma+n c_{r} Q(1-\gamma) e_{1}+n c_{a v} Q \gamma e_{2}+h_{v}\left\{\frac{n Q^{2}}{P}-\frac{n^{2} Q^{2}}{2 P}+\frac{n(n-1) Q^{2}(1-\gamma)\left(1-e_{1}\right)}{2 D}\right\}$. 


\subsection{The integrated vendor-buyer inventory model}

The total vendor-buyer integrated cost per production cycle is

$$
\begin{array}{r}
T C_{c}(n, Q)=T C_{v}(n, Q)+T C_{B}(n, Q)=S_{v}+S_{B}+n F+n c_{i} Q+n c_{w} Q \gamma+n c_{a} Q \gamma e_{2}+n c_{r} Q(1-\gamma) e_{1} \\
+n h_{B}\left\{\frac{Q^{2}}{x}\left[(1-\gamma) e_{1}+\gamma\left(1-e_{2}\right)\right]+\frac{Q^{2}\left\{1-\left(e_{1}+\gamma\right)+\gamma\left(e_{1}+2 e_{2}\right)\right\}(1-\gamma)\left(1-e_{1}\right)}{2 D}\right\}
\end{array}
$$

$+h_{v}\left\{\frac{n Q^{2}}{P}-\frac{n^{2} Q^{2}}{2 P}+\frac{n(n-1) Q^{2}(1-\gamma)\left(1-e_{1}\right)}{2 D}\right\}$.

Since the cycle time $T_{c}=n \frac{Q(1-\gamma)\left(1-e_{1}\right)}{D}$, one has

$$
E\left[T_{c}\right]=n \frac{Q(1-E[\gamma])\left(1-E\left[e_{1}\right]\right)}{D} .
$$

Using the renewal reward theorem, the expected total annual cost of the vendor and the buyer is

$$
\begin{aligned}
E T C(n, Q) & =\frac{E\left[T C_{c}(n, Q)\right]}{E\left[T_{c}\right]}=\frac{\left(S_{v}+S_{B}+n F\right) D}{n Q(1-E[\gamma])\left(1-E\left[e_{1}\right]\right)} \\
& +\frac{D\left\{c_{i}+c_{w} E[\gamma]+c_{a} E[\gamma] E\left[e_{2}\right]+c_{r}(1-E[\gamma]) E\left[e_{1}\right]\right\}}{(1-E[\gamma])\left(1-E\left[e_{1}\right]\right)} \\
& +h_{B} Q\left\{\frac{D\left\{(1-E\{\gamma]) E\left[e_{1}\right]+E[\gamma]\left(1-E\left[e_{2}\right]\right)\right\}}{x(1-E[\gamma])\left(1-E\left[e_{1}\right]\right)}+\frac{E[A]}{2(1-E[\gamma])\left(1-E\left[e_{1}\right]\right)}\right\} \\
& +h_{v}\left\{\frac{Q D}{P(1-E[\gamma])\left(1-E\left[e_{1}\right]\right)}-\frac{n D}{2 P(1-E[\gamma])\left(1-E\left[e_{1}\right]\right)}+\frac{(n-1) Q}{2}\right\},
\end{aligned}
$$

with

$$
\begin{aligned}
A & =\left\{1-\left(e_{1}+\gamma\right)+\gamma\left(e_{1}+2 e_{2}\right)\right\}(1-\gamma)\left(1-e_{1}\right) \\
& =1-2\left(\gamma+e_{1}\right)+4 \gamma e_{1}+2 \gamma e_{2}\left(1-e_{1}\right)+\gamma^{2}\left(1-2 e_{1}-2 e_{2}+2 e_{1} e_{2}+e_{1}^{2}\right)+e_{1}^{2}(1-2 \gamma),
\end{aligned}
$$

and

$E[A]=1-2\left(E[\gamma]+E\left[e_{1}\right]\right)+4 E[\gamma] E\left[e_{1}\right]+2 E[\gamma] E\left[e_{2}\right]\left(1-E\left[e_{1}\right]\right)$

$+E\left[\gamma^{2}\right]\left(1-2 E\left[e_{1}\right]-2 E\left[e_{2}\right]+2 E\left[e_{1}\right] E\left[e_{2}\right]+E\left[e_{1}^{2}\right]\right)+E\left[e_{1}^{2}\right](1-2 E[\gamma])$.

Taking the first derivative of $\operatorname{ETC}(n, Q)$ with respect to $Q$, we have

$$
\frac{\partial E T C(n, Q)}{\partial Q}=-\frac{\left(S_{v}+S_{B}+n F\right) D}{n Q^{2}(1-E[\gamma])\left(1-E\left[e_{1}\right]\right)}
$$




$$
\begin{aligned}
& +h_{B}\left\{\frac{D\left\{(1-E\{\gamma]) E\left[e_{1}\right]+E[\gamma]\left(1-E\left[e_{2}\right]\right)\right\}}{x(1-E[\gamma])\left(1-E\left[e_{1}\right]\right)}+\frac{E[A]}{2(1-E[\gamma])\left(1-E\left[e_{1}\right]\right)}\right\} \\
& +h_{\nu}\left\{\frac{D}{P(1-E[\gamma])\left(1-E\left[e_{1}\right]\right)}-\frac{n D}{2 P(1-E[\gamma])\left(1-E\left[e_{1}\right]\right)}+\frac{(n-1)}{2}\right\} .
\end{aligned}
$$

Taking the second derivative, we have

$$
\frac{\partial^{2} E T C(n, Q)}{\partial Q^{2}}=\frac{2\left(S_{v}+S_{B}+n F\right) D}{n Q^{3}(1-E[\gamma])\left(1-E\left[e_{1}\right]\right)}
$$

Note that if $E[\gamma]<1$ and $E\left[e_{1}\right]<1$, we have $\frac{\partial^{2} E T C(n, Q)}{\partial Q^{2}}>0$, which implies that at particular value of $n$, the total integrated annual cost is a convex function and there exists a unique value of $Q$ that minimizes Eq. (9), which is given as

$$
Q^{*}(n)=\sqrt{\frac{2\left(S_{v}+S_{B}+n F\right) D}{n\left[h_{v}\left((n-1)(1-E[\gamma])\left(1-E\left[e_{1}\right]\right)+(2-n) \frac{D}{P}\right)+h_{B}\left(2 \frac{D}{x}\left\{(1-E[\gamma]) E\left[e_{1}\right]+E[\gamma]\left(1-E\left[e_{2}\right]\right)\right\}+E[A]\right)\right]}}
$$

\subsection{Solution procedure}

The problem is to determine the value of $n$ that minimizes $\operatorname{ETC}(n, Q)$. Because the number of shipments per batch production run, $n$, is a discrete variable, one can find the optimal value of $n$ from the following procedure:

1. For a range of $n$ values, determine the corresponding $Q^{*}(n)$ using Eq.( 12$)$, and compute $\operatorname{ETC}\left(n, Q^{*}(n)\right)$ by substituting $Q^{*}(n)$ into Eq.(9).

2. Derive the optimal value of $n$, denoted by $n^{*}$, such that $\operatorname{ETC}\left(n, Q^{*}(n)\right) \leq \operatorname{ETC}\left(n-1, Q^{*}(n-1)\right)$, and

$$
\operatorname{ETC}\left(n, Q^{*}(n)\right) \leq \operatorname{ETC}\left(n+1, Q^{*}(n+1)\right) .
$$

Once we obtain the $n^{*}$ value, the optimal size of a production batch $Q_{P} *$ is given by $Q_{P}^{*}=n^{*} Q^{*}\left(n^{*}\right)$.

\subsection{The buyer's independent optimal solution}

If the vendor and the buyer do not work together in a cooperative manner towards maximizing their mutual benefits, and the buyer makes his own decisions independent of the vendor, then the vendor will produce and deliver the items to the buyer on a lot-for-lot basis. The buyer's expected annual cost is given as

$$
\begin{aligned}
E T C_{B}(Q) & =\frac{E\left[T C_{B}(n, Q)\right]}{E[T]}=\frac{\left(S_{B}+F\right) D}{Q(1-E[\gamma])\left(1-E\left[e_{1}\right]\right)}+\frac{D\left(c_{i}+c_{a B} E[\gamma] E\left[e_{2}\right]\right)}{(1-E[\gamma])\left(1-E\left[e_{1}\right]\right)} \\
& +h_{B} Q\left\{\frac{D\left\{(1-E\{\gamma]) E\left[e_{1}\right]+E[\gamma]\left(1-E\left[e_{2}\right]\right)\right\}}{x(1-E[\gamma])\left(1-E\left[e_{1}\right]\right)}+\frac{E[A]}{2(1-E[\gamma])\left(1-E\left[e_{1}\right]\right)}\right\},
\end{aligned}
$$


and the optimal solution is

$$
Q_{B}^{*}=\sqrt{\frac{2\left(S_{B}+F\right) D}{h_{B}\left(2 \frac{D}{x}\left\{(1-E[\gamma]) E\left[e_{1}\right]+E[\gamma]\left(1-E\left[e_{2}\right]\right)\right\}+E[A]\right)}} .
$$

The vendor's expected annual cost is given as

$$
\begin{aligned}
E T C_{v}(Q) & =\frac{E\left[T C_{c}(Q)\right]}{E[T]}=\frac{S_{v} D}{Q(1-E[\gamma])\left(1-E\left[e_{1}\right]\right)}+\frac{D\left\{c_{w} E[\gamma]+c_{r}(1-E[\gamma]) E\left[e_{1}\right]+c_{a v} E[\gamma] E\left[e_{2}\right]\right\}}{(1-E[\gamma])\left(1-E\left[e_{1}\right]\right)} \\
& +h_{v}\left\{\frac{Q D}{2 P(1-E[\gamma])\left(1-E\left[e_{1}\right]\right)}\right\} .
\end{aligned}
$$

If the decision is made solely from the buyer's perspective, then substituting $Q_{B}{ }^{*}$ into Eqs. (13) and (15), we obtain the buyer's and the vendor's expected annual costs respectively.

\section{Numerical examples and sensitivity analysis}

Consider an integrated vendor-buyer cooperative inventory model with the following parameters:

Production rate, $P$

Demand rate, $D$

Inspection rate, $x$

Setup cost for vendor, $S_{v}$

Ordering cost for buyer, $S_{B}$

Holding cost for vendor, $h_{v}$

Holding cost for buyer, $h_{B}$

Freight (transportation) cost, $F$

Inspection cost, $c_{i}$

The cost of producing a defective item, $c_{w}$

The cost of rejecting a non-defective item, $c_{r}$

The buyer's post-sale failure cost, $c_{a B}$

The vendor's post-sale failure cost, $c_{a_{v}}$
$=160,000$ units/year

$=50,000$ units/year

$=175,200$ units/year

$=\$ 300 /$ production run

$=\$ 100 /$ order

$=\$ 2 /$ unit/year

$=\$ 5 /$ unit/year

$=\$ 25 /$ delivery

$=\$ 0.5 /$ unit

$=\$ 50 /$ unit

$=\$ 100 /$ unit

$=\$ 200 /$ unit

$=\$ 300 /$ unit

If the defective percentage and inspections errors follow a uniform distribution with $f(\gamma)=\left\{\begin{array}{l}\frac{1}{\beta}, 0 \leq \gamma \leq \beta \\ 0, \text { otherwise }\end{array}\right.$ $f\left(e_{1}\right)=\left\{\begin{array}{l}\frac{1}{\lambda}, 0 \leq e_{1} \leq \lambda \\ 0, \text { otherwise }\end{array}\right.$ $f\left(e_{2}\right)=\left\{\begin{array}{l}\frac{1}{\eta}, 0 \leq e_{2} \leq \eta \\ 0, \text { otherwise }\end{array}\right.$

then, we have 
$E[\gamma]=\int_{0}^{\beta} \gamma f(\gamma) d \gamma=\int_{0}^{\beta} \frac{\gamma}{\beta} d \gamma=\frac{\beta}{2}, E\left[\gamma^{2}\right]=\int_{0}^{\beta} \gamma^{2} f(\gamma) d \gamma=\int_{0}^{\beta} \frac{\gamma^{2}}{\beta} d \gamma=\frac{\beta^{2}}{3}, E\left[e_{1}\right]=\frac{\lambda}{2}, E\left[e_{1}^{2}\right]=\frac{\lambda^{2}}{3}$, and $E\left[e_{2}\right]=\frac{\eta}{2}$. Specifically, if $\beta=\lambda=\eta=0.04$, we obtain the expected total annual cost of the vendor and the buyer as a function of $n$ and $Q$, which is given in Fig. 3.

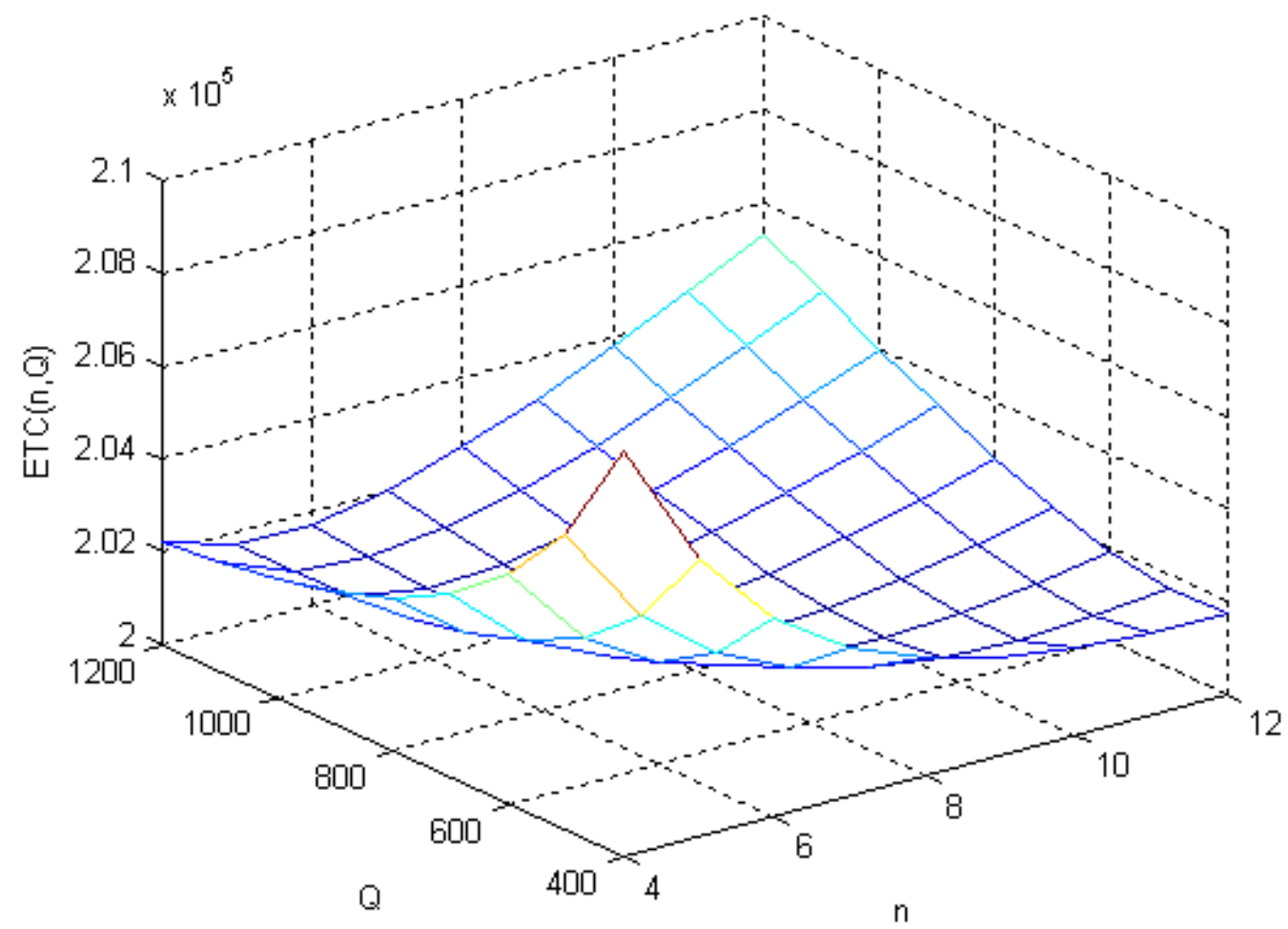

Fig. 3. The expected total annual cost of the vendor and the buyer

The three dimensional graph shows that the integrated expected total annual cost is convex, and that there exists a unique solution minimizing the integrated expected total annual cost. For the given example, the optimal solution is (see Table 1) $n^{*}=7, Q^{*}=791$, and the minimum total expected annual cost is $\$ 201,358.50$.

\section{Table 1}

Optimal solutions of $n, P=160,000, D=50,000, x=175,200, S_{v}=300, S_{B}=100$,

\begin{tabular}{llllll}
\multicolumn{5}{l}{$h_{v}=2, h_{B}=5, F=25, c_{i}=0.5, c_{w}=50, c_{r}=100, c_{a_{B}}=200, c_{a_{v}}=300, \beta=\lambda=\eta=0.04$} \\
\hline$n$ & $Q^{*}(n)$ & $E T C\left(n, Q^{*}(n)\right)$ & $n$ & $Q^{*}(n)$ & $E T C\left(n, Q^{*}(n)\right)$ \\
\hline 1 & $2,817.4942$ & $206,251.9011$ & 9 & 664.6448 & $201,424.7759$ \\
2 & $1,839.4721$ & $203,281.7266$ & 10 & 618.0560 & $201,496.0917$ \\
3 & $1,411.6533$ & $202,224.2429$ & 11 & 578.8818 & $201,583.0628$ \\
4 & $1,163.0292$ & $201,736.5636$ & 12 & 545.4389 & $201,681.3327$ \\
5 & 998.2423 & $201,497.8012$ & 13 & 516.5219 & $201,787.8688$ \\
6 & 880.1603 & $201,389.8054$ & 14 & 491.2447 & $201,900.5034$ \\
$7 *$ & $790.9983^{*}$ & $201,358.5041^{*}$ & 15 & 468.9401 & $202,017.6520$ \\
8 & 721.0770 & $201,375.5820$ & & & \\
\hline
\end{tabular}


Table 2 shows the optimal solutions for different freight costs. When the freight cost increases, the optimal number of deliveries per production batch from the vendor to the buyer decreases while the optimal size of the deliveries increases. The smaller the freight cost, the larger the cost reduction of the integrated model in comparison to an independent decision by the buyer is.

\section{Table 2}

Optimal solutions for different freight cost $F, P=160,000, D=50,000, x=175,200, S_{v}=300, S_{B}=100$ $h_{v}=2, h_{B}=5, c_{i}=0.5, c_{w}=50, c_{r}=100, c_{a B}=200, c_{a_{v}}=300, \beta=\lambda=\eta=0.04$.

\begin{tabular}{llllllll}
\hline & \multicolumn{2}{l}{ Buyer's independent decision } & \multicolumn{3}{c}{ Integrated model } & Cost \\
\cline { 2 - 6 }$F$ & $Q_{B}{ }^{*}$ & $E T C_{B}\left(Q_{B}{ }^{*}\right)$ & $E T C_{v}\left(Q_{B}{ }^{*}\right)$ & $n^{*}$ & $Q^{*}\left(n^{*}\right)$ & $E T C\left(n^{*}, Q^{*}\left(n^{*}\right)\right)$ & reduction \\
\hline 5 & $1,490.11$ & $37,532.75$ & $171,316.14$ & 16 & 347.87 & $199,525.14$ & $9,323.75$ \\
15 & $1,559.46$ & $37,874.19$ & $170,872.63$ & 9 & 614.93 & $200,611.04$ & $8,135.78$ \\
25 & $1,625.84$ & $38,201.07$ & $170,485.27$ & 7 & 791.00 & $201,358.50$ & $7,327.84$ \\
50 & $1,781.02$ & $38,965.14$ & $169,698.76$ & 5 & $1,110.74$ & $202,732.08$ & $5,931.82$ \\
100 & $2,056.55$ & $40,321.77$ & $168,613.54$ & 4 & $1,471.13$ & $204,701.17$ & $4,234.14$ \\
\hline
\end{tabular}

From Table 3, one can see that the smaller the vendor's holding cost is, the greater the advantages to deliver the items more frequently from the vendor to the buyer are, and the larger the cost reduction of the integrated model in comparison to an independent decision by the buyer is. Note that the optimal size of the production batch $Q_{P}{ }^{*}=n^{*} Q^{*}\left(n^{*}\right)$ decreases as the vendor's holding cost increases.

\section{Table 3}

Optimal solutions for different vendor's holding cost $h_{v}, P=160,000, D=50,000, x=175,200, S_{v}=300$ $S_{B}=100, h_{B}=5, F=25, c_{i}=0.5, c_{w}=50, c_{r}=100, c_{a_{B}}=200, c_{a_{v}}=300, \beta=\lambda=\eta=0.04$

\begin{tabular}{llllllll}
\hline & \multicolumn{3}{l}{ Buyer's independent decision } & \multicolumn{3}{l}{ Integrated model } & Cost \\
\cline { 2 - 6 }$h_{v}$ & $Q_{B}^{*}$ & $E T C_{B}\left(Q_{B}{ }^{*}\right)$ & $E T C_{v}\left(Q_{B}{ }^{*}\right)$ & $n^{*}$ & $Q^{*}\left(n^{*}\right)$ & $E T C\left(n^{*}, Q^{*}\left(n^{*}\right)\right)$ & reduction \\
\hline 1 & $1,625.84$ & $38,201.07$ & $170,220.75$ & 10 & 773.20 & $199,298.82$ & $9,123.00$ \\
2 & $1,625.84$ & $38,201.07$ & $170,485.27$ & 7 & 791.00 & $201,358.50$ & $7,327.84$ \\
3 & $1,625.84$ & $38,201.07$ & $170,749.78$ & 6 & 771.90 & $202,910.76$ & $6,040.09$ \\
4 & $1,625.84$ & $38,201.07$ & $171,014.29$ & 5 & 801.49 & $204,186.34$ & $5,029.02$ \\
5 & $1,625.84$ & $38,201.07$ & $171,278.80$ & 4 & 883.61 & $205,275.37$ & $4,204.50$ \\
\hline
\end{tabular}

Table 4 shows that the buyer's holding cost has a reverse impact as the vendor's holding cost does on the optimal solution. As the buyer's holding cost increases, the optimal number of deliveries per production batch increases, the optimal size of the deliveries decreases, and the cost reduction of the integrated model increases.

\section{Table 4}

Optimal solutions for different buyer's holding cost $h_{B}, P=160,000, D=50,000, x=175,200, S_{v}=300$, $S_{B}=100, h_{v}=2, F=25, c_{i}=0.5, c_{w}=50, c_{r}=100, c_{a B}=200, c_{a v}=300, \beta=\lambda=\eta=0.04$

\begin{tabular}{llllllll}
\hline & \multicolumn{2}{l}{ Buyer's independent decision } & \multicolumn{3}{l}{ Integrated model } & Cost \\
\cline { 2 - 6 }$h_{B}$ & $Q_{B}{ }^{*}$ & $E T C_{B}\left(Q_{B}{ }^{*}\right)$ & $E T C_{v}\left(Q_{B}{ }^{*}\right)$ & $n^{*}$ & $Q^{*}\left(n^{*}\right)$ & $E T C\left(n^{*}, Q^{*}\left(n^{*}\right)\right)$ & \\
\hline 2 & $2,570.69$ & $35,258.76$ & $167,261.93$ & 4 & $1,397.11$ & $199,861.53$ & $2,659.16$ \\
3 & $2,098.96$ & $36,396.65$ & $168,473.90$ & 5 & $1,102.05$ & $200,466.19$ & $4,404.36$ \\
5 & $1,625.84$ & $38,201.07$ & $170,485.27$ & 7 & 791.00 & $201,358.50$ & $7,327.84$ \\
8 & $1,285.34$ & $40,321.77$ & $172,919.31$ & 9 & 611.73 & $202,365.85$ & $10,875.23$ \\
10 & $1,149.65$ & $41,516.99$ & $174,309.41$ & 10 & 546.74 & $202,924.52$ & $12,901.88$ \\
\hline
\end{tabular}


Table 5 shows the sensitivity analysis on the defective percentage $\gamma$ (we assume that $\gamma$ is uniformly distributed between 0 and $\beta$ ). It is interesting to note that when $\beta$ increases, the optimal size of the deliveries first increases until it reaches its maximum value (at $\beta=0.3$ ) and then begins to decrease. The larger the $\beta$ value, the greater the cost reduction of the integrated model in comparison to an independent decision by the buyer is.

\section{Table 5}

Optimal solutions when the defective percentage $\gamma$ is uniformly distributed between 0 and $\beta$, $P=160,000, D=50,000, x=175,200, S_{v}=300, S_{B}=100, h_{v}=2, h_{B}=5, F=25, c_{i}=0.5, c_{w}=50, c_{r}$ =100, $c_{a_{B}}=200, c_{a v}=300, \lambda=\eta=0.04$.

\begin{tabular}{llllllll}
\hline \multirow{3}{*}{$\beta$} & \multicolumn{3}{l}{ Buyer's independent decision } & \multicolumn{3}{l}{ Integrated model } & Cost \\
\cline { 2 - 6 } & $Q_{B}^{*}$ & $E T C_{B}\left(Q_{B}{ }^{*}\right)$ & $E T C_{v}\left(Q_{B}^{*}\right)$ & $n^{*}$ & $Q^{*}\left(n^{*}\right)$ & $E T C\left(n^{*}, Q^{*}\left(n^{*}\right)\right)$ & reduction \\
\hline 0.04 & $1,625.84$ & $38,201.07$ & $170,485.27$ & 7 & 791.00 & $201,358.50$ & $7,327.84$ \\
0.06 & $1,636.89$ & $40,644.24$ & $200,584.08$ & 7 & 796.51 & $233,865.75$ & $7,362.57$ \\
0.08 & $1,647.95$ & $43,139.00$ & $231,310.79$ & 7 & 802.11 & $267,050.22$ & $7,399.57$ \\
0.1 & $1,659.01$ & $45,687.01$ & $262,685.25$ & 7 & 807.79 & $300,933.30$ & $7,438.96$ \\
0.2 & $1,714.14$ & $59,288.32$ & $430,029.96$ & 7 & 837.43 & $481,642.81$ & $7,675.47$ \\
0.3 & $1,768.32$ & $74,512.44$ & $617,089.11$ & 7 & 869.36 & $683,611.83$ & $7,989.72$ \\
0.4 & $1,820.53$ & $91,666.00$ & $827,561.59$ & 8 & 825.82 & $910,818.78$ & $8,408.81$ \\
\hline
\end{tabular}

From Table 6, one can see that the Type I error $e_{1}$ (we assume $e_{1}$ is uniformly distributed between 0 and $\lambda$ ) has a similar impact as the defective percentage $\gamma$ does on the optimal solution. When $\lambda$ increases, the optimal size of the deliveries first increases until it reaches its maximum value (at $\lambda$ $=0.3$ ) and then begins to decrease. The larger the $\lambda$ value, the greater the cost reduction of the integrated model in comparison to an independent decision by the buyer is.

\section{Table 6}

Optimal solutions when the probability of Type I error $e_{1}$ is uniformly distributed between 0 and $\lambda$, $P=160,000, D=50,000, x=175,200, S_{v}=300, S_{B}=100, h_{v}=2, h_{B}=5, F=25, c_{i}=0.5, c_{w}=50, c_{r}$ =100, $c_{a_{B}}=200, c_{a_{v}}=300, \beta=\eta=0.04$.

\begin{tabular}{llllllll}
\hline \multirow{2}{*}{$\lambda$} & \multicolumn{3}{l}{ Buyer's independent decision } & \multicolumn{3}{l}{ Integrated model } & Cost \\
\cline { 2 - 6 } & $Q_{B}^{*}$ & $E T C_{B}\left(Q_{B}{ }^{*}\right)$ & $E T C_{v}\left(Q_{B}^{*}\right)$ & $n^{*}$ & $Q^{*}\left(n^{*}\right)$ & $E T C\left(n^{*}, Q^{*}\left(n^{*}\right)\right)$ & reduction \\
\hline 0.04 & $1,625.84$ & $38,201.07$ & $170,485.27$ & 7 & 791.00 & $201,358.50$ & $7,327.84$ \\
0.06 & $1,637.12$ & $38,539.19$ & $223,726.09$ & 7 & 796.55 & $254,904.55$ & $7,360.73$ \\
0.08 & $1,648.41$ & $38,885.07$ & $278,076.98$ & 7 & 802.19 & $309,566.14$ & $7,395.91$ \\
0.1 & $1,659.70$ & $39,238.99$ & $333,573.00$ & 7 & 807.91 & $365,378.51$ & $7,433.48$ \\
0.2 & $1,715.94$ & $41,139.06$ & $629,566.68$ & 7 & 837.75 & $663,044.47$ & $7,661.27$ \\
0.3 & $1,771.15$ & $43,286.37$ & $960,411.21$ & 7 & 869.87 & $995,730.00$ & $7,967.58$ \\
0.4 & $1,824.25$ & $45,729.78$ & $1,332,643.69$ & 8 & 826.39 & $1,369,994.36$ & $8,379.11$ \\
\hline
\end{tabular}

Table 7 shows the sensitivity analysis of the Type II error $e_{2}$. (We assume $e_{2}$ is uniformly distributed between 0 and $\eta$ ). When $\eta$ increases, the optimal size of the shipments decreases, and the cost reduction increases. Both of the changes are slight, indicating that the optimal solution is not sensitive to the Type II error. From the numerical examples, one can see that the integrated model results in an impressive cost reduction in comparison to an independent decision by the buyer. 


\section{Table 7}

Optimal solutions when the probability of Type II error $e_{2}$ is uniformly distributed between 0 and $\eta$, $P=160,000, D=50,000, x=175,200, S_{v}=300, S_{B}=100, h_{v}=2, h_{B}=5, F=25, c_{i}=0.5, c_{w}=50, c_{r}$ $=100, c_{a_{B}}=200, c_{a_{v}}=300, \beta=\lambda=0.04$

\begin{tabular}{llllllll}
\hline \multirow{7}{\eta}{$\eta$} & \multicolumn{3}{l}{ Buyer's independent decision } & \multicolumn{2}{l}{ Integrated model } & Cost \\
\cline { 2 - 6 } & $Q_{B} *$ & $E T C_{B}\left(Q_{B}{ }^{*}\right)$ & $E T C_{v}\left(Q_{B}{ }^{*}\right)$ & $n^{*}$ & $Q^{*}\left(n^{*}\right)$ & $E T C\left(n^{*}, Q^{*}\left(n^{*}\right)\right)$ & reduction \\
\hline 0.04 & $1,625.84$ & $38,201.07$ & $170,485.27$ & 7 & 791.00 & $201,358.50$ & $7,327.84$ \\
0.06 & $1,625.62$ & $40,284.67$ & $173,610.25$ & 7 & 790.96 & $206,565.22$ & $7,329.70$ \\
0.08 & $1,625.39$ & $42,368.27$ & $176,735.23$ & 7 & 790.92 & $211,771.93$ & $7,331.57$ \\
0.1 & $1,625.16$ & $44,451.86$ & $179,860.21$ & 7 & 790.88 & $216,978.65$ & $7,333.42$ \\
0.2 & $1,624.01$ & $54,869.85$ & $195,485.11$ & 7 & 790.68 & $243,012.22$ & $7,342.74$ \\
0.3 & $1,622.87$ & $65,287.82$ & $211,110.01$ & 7 & 790.48 & $269,045.79$ & $7,352.04$ \\
0.4 & $1,621.72$ & $75,705.80$ & $226,734.91$ & 7 & 790.27 & $295,079.36$ & $7,361.35$ \\
\hline
\end{tabular}

\section{Conclusion and future research}

In this paper, we develop an integrated vendor-buyer production-inventory model for items with imperfect quality and inspection errors. The objective is to minimize the total joint annual costs incurred by the vendor and the buyer. The production process is imperfect and produces a certain number of defective items with a known probability density function. We consider the policy in which the delivery quantity to the buyer is identical at each delivery. Once the buyer receives the lot, a $100 \%$ screening process of the lot is conducted, and the screening process and demand proceed simultaneously. The screening process is not perfect. The inspector may incorrectly classify a nondefective item as defective (a Type I inspection error), or incorrectly classify a defective item as nondefective (a Type II inspection error). The expected total integrated annual cost of the vendor and the buyer is derived and a solution procedure is provided to find the optimal solution that minimizes the expected total integrated annual cost. Numerical examples show that the integrated model gives an impressive cost reduction in comparison to an independent decision by the buyer.

This paper assumes that the defective items are sold to a secondary market at a discounted price. One possible extension of this research is to have the vendor rework the defective items and convert the defective items into good quality products to satisfy the buyer's demand. Another possible extension of our model is to consider the case where, while some customers are willing to exchange the defective items with good ones, others may be disappointed at the product quality and ask for a full price refund (i.e., the case of lost sales). Finally, we use the just in time philosophy to assume that the successive deliveries of the items from the vendor to the buyer are arranged in such a way that the items arrive at the buyer's place when the buyer's inventories from the previous delivery have just been depleted. Thus, one may extend our model by allowing shortages to occur and to be completely or partially backordered.

\section{References}

Aderohunmu, R., Mobolurin, A., \& Bryson, N. (1995). Joint vendor-buyer policy in JIT manufacturing. Journal of the Operational Research Society, 46, 375-385.

Ben-Daya, M., \& Hariga, M. (2000). Economic lot scheduling problem with imperfect production processes. Journal of the Operational Research Society, 51, 875-881.

Ben-Daya, M., \& Al-Nassar, A. (2008). An integrated inventory production system in a three- layer supply chain. Production Planning and Control, 19, 97-104.

Ben-Daya, M., Darwish, M., \& Ertogral, K. (2008). The joint economic lot sizing problem: Review and extensions. European Journal of Operational Research, 185, 726-742. 
Banerjee, A. (1986). A joint economic-lot-size model for purchaser and vendor. Decision Sciences, 17, 292-311.

Cárdenas-Barrón, L.E. (2009). Economic production quantity with rework process at a single-stage manufacturing system with planned backorders. Computers and Industrial Engineering, 57, 11051113.

Chan, C., \& Kingsman, B. (2007). Coordination in a single-vendor multi-buyer supply chain by synchronizing delivery and production cycles. Transportation Research Part E, 43, 90-111.

Chang, H.C., Ouyang, L.Y., Wu, K.S., \& Ho, C.H. (2006). Integrated vendor-buyer cooperative inventory models with controllable lead time and ordering cost reduction. European Journal of Operational Research, 170, 481-495.

Chung, K.J. (2008). An improvement of an integrated single-vendor single-buyer inventory model with shortage. Production Planning and Control, 19, 275-277.

Chung, K.J.(2011). The economic production quantity with rework process in supply chain management. Computers and Mathematics with Applications, 62, 2547-2550.

Duffuaa, S.O., \& Khan, M. (2002). An optimal repeat inspection plan with several classifications. Journal of the Operational Research Society, 53, 1016-1026.

Duffuaa, S.O., \& Khan, M. (2005). Impact of inspection errors on the performance measures of a general repeat inspection plan. International Journal of Production Research, 43, 4945-4967.

Ertogral, K., Darwish, M., \& Ben-Daya, M. (2007). Production and shipment lot sizing in a vendorbuyer supply chain with transportation cost. European Journal of Operational Research, 176, 15921606.

Goyal, S.K.(1976). An integrated inventory model for a single supplier-single customer problem. International Journal of Production Research, 15, 107-111.

Goyal, S.K.(1988). A joint economic-lot-size model for purchaser and vendor: a comment. Decision Sciences, 19, 236-241.

Goyal, S.K.(1995). A one-vendor multi-buyer integrated inventory model: a comment. European Journal of Operational Research, 82, 209-210.

Goyal, S.K., \& Cárdenas-Barrón, L.E. (2002). Note on: economic production quantity model for items with imperfect quality - a practical approach. International Journal of Production Economics, 77, 85-87.

Goyal, S.K., \& Gupta, Y.P. (1989). Integrated inventory models: the buyer-vendor Coordination. European Journal of Operational Research, 41, 261-269.

Goyal, S.K., Huang, C.K., \& Chen, K.C. (2003). A simple integrated production policy of an imperfect item for vendor and buyer. Production Planning and Control 14 (7), 596-602.

Goyal, S.K., \& Nebebe, F. (2000). Determination of economic production-shipment policy for a single-vendor single-buyer system. European Journal of Operational Research, 121, 175-178.

Goyal, S.K., \& Szendrovits, A.Z. (1986). A constant lot size model with equal and unequal size batch shipments between production stages. Engineering Costs and Production Economics, 10, 203-210.

Ha, D., \& Kim, S.L. (1997). Implementation of JIT purchasing: an integrated approach. Production Planning and Control, 8,152-157.

Hill, R.M. (1997). The single-vendor single-buyer integrated production-inventory model with a generalized policy. European Journal of Operational Research, 97, 493-499.

Hill, R.M. (1999). The optimal production and shipment policy for the single-vendor single-buyer integrated production- inventory model. International Journal of Production Research, 37, 24632475.

Hill, R.M., \& Omar, M. (2006). Another look at the single-vendor single-buyer integrated production inventory problem. International Journal of Production Research, 44, 791-800.

Hoque, M.A., \& Goyal, S.K. (2000). An optimal policy for a single-vendor single-buyer integrated production-inventory system with capacity constraint of the transport equipment. International Journal of Production Economics, 65, 305-315. 
Hoque, M.A., \& Goyal, S.K. (2006). A heuristic solution procedure for an integrated inventory system under controllable lead-time with equal or unequal sized batch shipments between a vendor and a buyer. International Journal of Production Economics, 102, 217-225.

Hsu, L.F. (2012) A note on "An economic order quantity (EOQ) for items with imperfect quality and inspection errors." International Journal of Industrial Engineering Computations, 3, 695-702.

Huang, C.K. (2002). An integrated vendor-buyer cooperative inventory model for items with imperfect quality. Production Planning and Control, 13, 355-361.

Huang, C.K. (2004). An optimal policy for a single-vendor single-buyer integrated productioninventory problem with process unreliability consideration. International Journal of Production Economics, 91, 91-98.

Huang, C.K., Tsai, D.M., Wu, J.C., \& Chung, K.J. (2010a). An integrated vendor-buyer inventory model with order-processing cost reduction and permissible delay in payments. European Journal of Operational Research, 202, 473-478.

Huang, C.K., Tsai, D.M., Wu, J.C., \& Chung, K.J. (2010b). An optimal integrated vendor-buyer inventory policy under conditions of order-processing time reduction and permissible delay in payments. International Journal of Production Economics, 128, 445-451.

Khan, M., Jaber, M.Y., Guiffrida, A.L., \& Zolfaghari, S. (2011a). A review of the extensions of a modified EOQ model for imperfect quality items. International Journal of Production Economics, 132, 1-12.

Khan, M., Jaber, M.Y., \& Maurice, B. (2011b). An economic order quantity (EOQ) for items with imperfect quality and inspection errors. International Journal of Production Economics, 133, 113118.

Kok, A.G., \& Shang, K.H. (2007). Inspection and replenishment policies for systems with inventory record inaccuracy. Manufacturing and Service Operations Management, 9, 185-205.

Lee, H.L., \& Rosenblatt, M.J. (1987). Simultaneous determination of production cycles and inspection schedules in a production system. Management Science, 33, 1125-1137.

Liao, G.L., \& Sheu, S.H. (2011). Economic production quantity model for randomly failing production process with minimal repair and imperfect maintenance. International Journal of Production Economics, 130, 118-124.

Lin, T.Y. (2009). Optimal policy for a simple supply chain system with defective items and returned cost under screening errors. Journal of the Operations Research Society of Japan, 52, 307-320.

Lo, S.T., Wee, H.M., \& Huang, W.C. (2007). An integrated production-inventory model with imperfect production processes and Weibull distribution deterioration under inflation. International Journal of Production Economics, 106, 248-260.

Lu, L. (1995). A one-vendor multi-buyer integrated inventory model. European Journal of Operational Research, 81, 312-323.

Ouyang, L.Y., Wu, K.S., \& Ho, C.H. (2004). Integrated vendor-buyer cooperative models with stochastic demand in controllable lead time. International Journal of Production Economics, 92, 255-266.

Porteus, E.L. (1986). Optimal lot sizing, process quality improvement and setup cost reduction. Operations Research, 34, 137-144.

Raouf, A., Jain, J.K., \& Sathe, P.T. (1983). A cost-minimization model for multicharacteristic component inspection. IIE Transactions, 15, 187-194.

Salameh, M.K., \& Jaber, M.Y. (2000). Economic production quantity model for items with imperfect quality. International Journal of Production Economics, 64, 59-64.

Sana, S.S. (2010). An economic production lot size model in an imperfect production system. European Journal of Operational Research, 201, 158-170.

Sarmah, S.P., Acharya, D., \& Goyal, S.K. (2006). Buyer vendor coordination models in supply chain management. European Journal of Operational Research, 175, 1-15.

Schwaller, R.L. (1988). EOQ under inspection costs. Production and Inventory Management, 29, 2224. 
Siajadi, H., Ibrahim, R., \& Lochert, P. (2006). A single-vendor multiple-buyer inventory model with a multiple-shipment policy. International Journal of Advanced Manufacturing Technology, 27, 10301037.

Viswanathan, S. (1998). Optimal strategy for the integrated vendor-buyer inventory model. European Journal of Operational Research, 105, 38-42.

Wu, K.S., \& Ouyang, L.Y. (2003). An integrated single-vendor single-buyer inventory system with shortage derived algebraically. Production Planning and Control, 14, 555-561.

Yoo, S.H., Kim, D., \& Park, M.S.(2009). Economic production quantity model with imperfect-quality items, two-way imperfect inspection and sales return. International Journal of Production Economics, 121, 255-265.

Zhou, Y., \& Wang, S. (2007). Optimal production and shipment models for a single-vendor-singlebuyer integrated system. European Journal of Operational Research, 180, 309-328. 